Research Paper

\title{
XPA gene polymorphisms and risk of neuroblastoma in Chinese children: a two-center case-control study
}

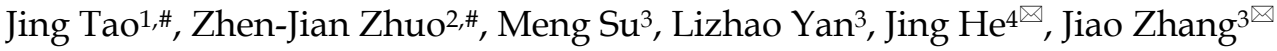 \\ 1. Department of Pathology, Children's Hospital Affiliated to Zhengzhou University, Henan Children's Hospital, Zhengzhou Children's Hospital, Zhengzhou \\ 450053, Henan, China \\ 2. School of Chinese Medicine, Faculty of Medicine, The Chinese University of Hong Kong, Hong Kong 999077, China \\ 3. Department of Pediatric Surgery, the First Affiliated Hospital of Zhengzhou University, Zhengzhou 450052, Henan, China \\ 4. Department of Pediatric Surgery, Guangzhou Institute of Pediatrics, Guangzhou Women and Children's Medical Center, Guangzhou Medical University, \\ Guangzhou 510623, Guangdong, China \\ \# These authors contributed equally to this work. \\ $\triangle$ Corresponding authors: Jiao Zhang, Department of Pediatric Surgery, the First Affiliated Hospital of Zhengzhou University, 1 East Jianshe Road, Zhengzhou \\ 450052, Henan, China, Tel./Fax: (+86- 0371) 66279071, Email: zhangiiaomail@126.com; or Jing He, Department of Pediatric Surgery, Guangzhou Institute of \\ Pediatrics, Guangzhou Women and Children's Medical Center, Guangzhou Medical University, 9 Jinsui Road, Guangzhou 510623, Guangdong, China, Tel./Fax: \\ (+86-020) 38076560, Email: hejing@gwcmc.org. \\ (c) Ivyspring International Publisher. This is an open access article distributed under the terms of the Creative Commons Attribution (CC BY-NC) license \\ (https:// creativecommons.org/licenses/by-nc/4.0/). See http://ivyspring.com/terms for full terms and conditions.
}

Received: 2018.03.09; Accepted: 2018.06.09; Published: 2018.07.01

\begin{abstract}
Neuroblastoma is a malignant tumor arising from the developing sympathetic nervous system, which mainly affects children. Variations in XPA gene have been shown to confer cancer susceptibility. However, no investigation has been reported regarding the association between XPA polymorphisms and neuroblastoma risk. This study was conducted to measure the association of XPA polymorphisms with neuroblastoma susceptibility in Chinese children. In this hospital-based case-control study with 393 cases and 812 controls, we genotyped two polymorphisms (rs 1800975 $\mathrm{T}>\mathrm{C}$, and rs3176752 G>T) in XPA gene to access their contributions to neuroblastoma risk by TaqMan methods. The strength of the association with neuroblastoma risk was estimated by odds ratios (ORs) and $95 \%$ confidence intervals (Cls). No single polymorphism was found to predispose to neuroblastoma susceptibility. When risk genotypes were combined, we found that carriers of 1-2 risk genotypes had significantly increased neuroblastoma risk (adjusted $O R=1.28 ; 95 \%$ $\mathrm{Cl}=1.001-1.64, P=0.049$ ), when compared to non-carriers. Stratification analysis by age, gender, sites of origin and clinical stages failed to show any significant association. Our study provides cues that XPA gene polymorphisms may exert a weak effect in neuroblastoma risk. This finding needs further validations by larger sample size studies.
\end{abstract}

Key words: neuroblastoma; XPA; polymorphism; susceptibility

\section{Introduction}

Neuroblastoma, a solid cancer originating from neural crest progenitor cells, is one of the most common tumors in children [1]. The median age at diagnosis of neuroblastoma is about 17 months. Neuroblastoma accounts for approximately $10 \%$ of all pediatric cancers, yet its proportion of all pediatric cancer mortality accounts for up to $15 \%$ [2]. The incidence rate of neuroblastoma in China is about 1 out of 13,000 [3]. In contrast, America witnesses is much higher, nearly 1 out of 7000 [4]. Neuroblastoma is characterized by high heterogeneity in its clinical phenotypes and symptoms [5]. Based on the clinical, pathologic, and prognostic factors, neuroblastoma cases are generally classified into low-, intermediate-, high- and ultra-high-risk groups [6]. Among them, high- and ultra-high-risk groups constitute around $50 \%$ of all cases. The outcome of these high- and ultra-high-risk groups are poor, with less than $40 \%$ cases achieving long-term survival [1]. Poor prognosis was mainly attributed to the widespread metastasis of tumor at the time of diagnosis $[7,8]$. 
Approximately $1-2 \%$ of all cases of neuroblastoma are familial [5]. Using large-scale genetic linkage studies, several candidate predisposition chromosomal regions $(2 p, 12 p$, and $16 p)$ have been found to associate with familial neuroblastoma risk $[9,10]$. These findings further led to the discovery of certain gene mutations. Most of the familial cases have highly penetrant mutations in $P H O X 2 B[11,12]$ and $A L K$ gene [13]. However, the underlying etiology of sporadic neuroblastoma, the most common form, remains to be elucidated. Although environmental factors such as the conception and pregnancy exposures are potential risk of sporadic neuroblastoma, direct link between has not yet been established [14, 15].

Expanding body of evidence has suggested that genetic factors and genetic-environmental interactions could contribute to the susceptibility of neuroblastoma. Recent genome-wide association studies (GWASs) have identified several neuroblastoma susceptibility loci, including single nucleotide polymorphisms (SNPs) in HACE1, LIN28B, BARD1, CASC15, TP53, and LMO1 [16-21]. The association of neuroblastoma risk with $L M O 1, B A R D 1, L I N 28 B$, and TP53 polymorphisms have been confirmed in many replication case-control studies [22-26]. Another powerful way to investigate the role of gene polymorphisms in cancer risk is to analyze the genetic linkage between potential functional SNPs in core genes and cancer susceptibility. This method could overcome the limitation of GWAS, as most of the GWAS-identified SNPs only have modest risk effects due to the adoption of restricted $P$-value $\left(1 \times 10^{5}\right)$ [27]. Therefore, additional neuroblastoma susceptibility loci or gene polymorphisms are warranted to be identified.

The stability of cellular functions and genomic integrity is primarily maintained by DNA repair systems [28]. Among the various DNA repair systems, the nucleotide excision repair (NER) pathway is responsible for excising bulky DNA lesions [29]. A myriad of evidences have proven that defects in NER pathway might weaken the DNA repair capacity and thus predispose to cancer risks [30]. The NER process mainly consists of four steps: damage recognition, unwinding of the DNA, removal of the damage, and ligation [31,32]. Eight critical genes (XPA-XPG and $E R C C 1)$ participate in the repair process and coordinately maintain genomic integrity [33]. XPA (xeroderma pigmentosum complementary group $A$ ) gene encodes a zinc finger DNA binding protein. This DNA binding-protein, XPA, is essential in organizing the DNA damage site and then functioning as a scaffold to excise lesions [34, 35]. Owing to the important role of XPA protein in NER pathway, the association between XPA polymorphisms and cancer risk remains a hot spot of research. By now, several epidemiological studies have been performed to determine of the association with the risk of cancer, including colorectal cancer [36], laryngeal cancer [37], lung cancer [38], and B-cell lymphoma [39].

Because of the universal importance of XPA in cancer, we conducted a case-control study to determine whether the SNPs in XPA gene could predispose to neuroblastoma in Chinese population.

\section{Materials and methods}

\section{Study subjects}

Totally, 393 cases with neuroblastoma and 812 healthy controls were recruited in this hospital-based epidemiological study [40-42]. To be specific, 275 cases and 531 controls were from Guangzhou Women and Children's Medical Center and the rest were from The First Affiliated Hospital of Zhengzhou University $[25,43,44]$. All the participants were unrelated Chinese Han children. Written informed consent was provided before the study by all participants or their guardians. The study protocols obtained approval from the Institutional Review Board of Guangzhou Women and Children's Medical Center and the Institutional Review Board of The First Affiliated Hospital of Zhengzhou University.

\section{SNP selection and genotyping}

We chose potentially functional polymorphisms of XPA gene from dbSNP database (http://www. ncbi.nlm.nih.gov/) and an online tool, SNPinfo (http:// snpinfo.niehs.nih.gov/) using the selection criteria described in our published studies [45]. Two SNPs (rs1800975 T>C, and rs3176752 G>T) in the XPA gene were selected in the final analysis. In them, rs1800975 T>C might affect transcription activity, while rs3176752 G>T might affect the microRNA binding site activity. Genomic DNA was extracted from peripheral blood donated by all the included subjects using a TIANamp Blood DNA Kit (TianGen Biotech Co. Ltd., Beijing, China). TaqMan real-time PCR was performed to genotype the selected SNPs. The details of genotyping protocol could be obtained in previous studies [46-49]. As a quality control, 10\% of the random samples were carried out twice. A concordance rate of $100 \%$ was got for all duplicate sets.

\section{Statistical analysis}

First, deviation from Hardy-Weinberg equilibrium (HWE) of the selected SNPs among controls was assessed by goodness-of-fit $X^{2}$ test. Two-sided chi-squared test was used to identify the difference of the demographic variables and allele frequencies between the cases and controls. Logistic 
regression analysis, served to provide odds ratios (ORs) and 95\% confidence intervals (CIs), was adopted to estimate the association between XPA SNPs and neuroblastoma risk. Significance was achieved when $P$ values were less than 0.05 . All statistical analyses were performed using the version 9.4 SAS statistical package (SAS Institute, Cary, NC).

\section{Results}

\section{Correlation of XPA gene polymorphisms with neuroblastoma susceptibility}

The detailed characteristics of all the cases and controls could be found in our previously published articles [40-42]. In brief, no statistically significant differences were found between cases and controls regarding age $(P>0.05)$ and gender $(P>0.05)$. According to the INSS criteria, 69 (17.56\%), 93 (23.66\%), $68(17.30 \%), 143(36.39 \%)$, and $11(2.80 \%)$ patients were diagnosed with clinical stages I, II, III, $\mathrm{IV}$, and $4 \mathrm{~s}$ disease, respectively. In terms of tumor sites, $153(38.93 \%)$ neuroblastomas occurred in the adrenal glands, 109 (27.74\%) in the mediastinum, 87 $(22.14 \%)$ in retroperitoneal regions, and $36(9.16 \%)$ in other regions. To evaluate the relationship between these two SNPs as well as the combined risk genotypes of XPA gene (rs1800975 T>C, rs3176752 G $>$ T) and risk of neuroblastoma, crude and adjusted ORs and their 95\% CIs were calculated. The main results of the above calculations were listed in Table 1. In general, we failed to detect any statistically significant differences in the genotype frequencies distribution of rs1800975 $\mathrm{T}>\mathrm{C}$ or $\mathrm{rs} 3176752 \mathrm{G}>\mathrm{T}$ polymorphism. Moreover, none of the two polymorphisms were significantly associated with neuroblastoma risk. The allele frequencies for controls in both rs1800975 and rs3176752 genotypes were in Hardy-Weinberg equilibrium, with $P$ values equal to 0.068 and 0.416 , respectively. Further analysis of the combined effect of risk genotypes revealed that 1-2 combined risk genotypes was markedly associated with an increased risk of neuroblastoma, compared with those without any risk genotypes (adjusted $\mathrm{OR}=1.28 ; 95 \% \mathrm{CI}=1.001-1.64, P=0.049)$.

\section{Stratification analysis of XPA gene polymorphisms with neuroblastoma susceptibility}

We further conducted subgroup analyses by age, gender, tumor sites of origin and clinical stages to evaluate the contributions of the selected polymorphisms and their combined risk genotypes to the risk of neuroblastoma (Table 2). However, the calculated results indicated that there lacks significant difference association between the selected polymorphisms as well as their combined risk genotypes and neuroblastoma risk under any of the evaluated subgroups.

\section{Haplotype analysis}

As shown in Table 3, we did not find any haplotype can influence neuroblastoma susceptibility significantly.

\section{Discussion}

In order to identify the association between XPA SNPs and neuroblastoma risk, we conducted a two-center case-control study by recruiting 393 neuroblastoma patients and 812 healthy control subjects from Chinese population. Our results indicated that variations in XPA gene had no significant association with neuroblastoma risk. To the best of our knowledge, this is the first study investigating the associations in Chinese children.

$X P A$ gene is mapped to chromosome 9p22.3. It encodes a relatively small 273-residue protein without enzymatic activity. Alternatively, XPA functions as a scaffold by interacting with many other NER proteins such as replication protein $\mathrm{A}$, transcription factor $\mathrm{IIH}$ and excision repair cross complementing group 1-xeroderma pigmentosum group $\mathrm{F}$ protein complex [50]. Through interacting with these proteins, XPA protein facilitates the formation of the assembly and structural organization of human NER incision complexes [51]. Current evidence indicates that mutations in XPA gene impairs normal function of NER [51]. Thus, it is biologically reasonable that functional XPA gene variants may influence the DNA repair capacity, and thereby modify cancer risk. A vast number of studies has been performed to investigate the association of XPA gene SNPs with cancer risk. For example, the rs $1800975 \mathrm{~T}>\mathrm{C}$ polymerphism of XPA gene has been reported to be associated with increased risk of colorectal cancer in a study conducted in Poland [36]. Another study conducted in Norway indicated that XPA gene rs1800975 T $>C$ was associated with a significant reduction in the risk of lung cancer [52]. The discrepancy results suggested that the same polymorphism might have different roles in cancer susceptibility depending on cancer sites and ethnicities, not to mention the different polymorphisms in candidate gene.

Herein, for the first time we explored whether XPA gene SNPs could affect neuroblastoma susceptibility in Chinese children. Unexpectedly, neither of the two polymorphisms of XPA gene was associated with neuroblastoma risk, in the overall analysis and stratified analysis. The null association might be partially attributed to the limited statistical power caused by relatively small sample size. Moreover, the low-penetrance of single polymorph- 
ism might also account for such a null association. Neuroblastoma is a multifactorial and complex disease resulting from interplay between multiple genetic and environmental factors $[1,5,53]$. Previous study has demonstrated that polymorphisms in individual genes might not have enough impact on the risk of cancer [54]. Thus, it would be expected that the combined SNPs might have greater effects. Indeed, combined analysis revealed that 1-2 combined risk genotypes was markedly associated with an increased risk of neuroblastoma, compared with 0 risk genotypes. Consistent with our results, Tse et al. [55], found that compared with one variant allele alone, the combined four NER SNPs could significantly increase risk of esophageal adenocarcinoma. Similar variant-dosage effect was also observed in our former case-control study in other NER genes [56].

Table 1. Logistic regression analysis for the association between XPA gene polymorphisms and neuroblastoma susceptibility

\begin{tabular}{|c|c|c|c|c|c|c|c|}
\hline Genotype & Cases $(\mathrm{N}=393)$ & Controls $(\mathrm{N}=812)$ & $P a$ & Crude OR $(95 \% \mathrm{CI})$ & $P$ & Adjusted OR $(95 \% \mathrm{CI})^{\mathrm{b}}$ & $P^{b}$ \\
\hline \multicolumn{8}{|c|}{ rs1800975 (HWE=0.068) } \\
\hline TT & $111(28.24)$ & $191(23.52)$ & & 1.00 & & 1.00 & \\
\hline TC & $197(50.13)$ & $432(53.20)$ & & $0.79(0.59-1.05)$ & 0.099 & $0.79(0.59-1.05)$ & 0.101 \\
\hline $\mathrm{CC}$ & $85(21.63)$ & $189(23.28)$ & & $0.77(0.55-1.10)$ & 0.147 & $0.78(0.55-1.10)$ & 0.150 \\
\hline Additive & & & 0.207 & $0.88(0.74-1.04)$ & 0.134 & $0.88(0.74-1.04)$ & 0.137 \\
\hline Dominant & $282(71.76)$ & $621(76.48)$ & 0.076 & $0.78(0.60-1.03)$ & 0.077 & $0.78(0.60-1.03)$ & 0.079 \\
\hline Recessive & $308(78.37)$ & $623(76.72)$ & 0.522 & $0.91(0.68-1.22)$ & 0.523 & $0.91(0.68-1.22)$ & 0.527 \\
\hline \multicolumn{8}{|c|}{ rs3176752 (HWE=0.416) } \\
\hline GG & $301(76.59)$ & $639(78.69)$ & & 1.00 & & 1.00 & \\
\hline GT & $83(21.12)$ & $160(19.70)$ & & $1.10(0.82-1.48)$ & 0.526 & $1.10(0.82-1.49)$ & 0.516 \\
\hline TT & $9(2.29)$ & $13(1.60)$ & & $1.47(0.62-3.48)$ & 0.381 & $1.47(0.62-3.48)$ & 0.382 \\
\hline Additive & & & 0.576 & $1.13(0.88-1.46)$ & 0.331 & $1.14(0.88-1.47)$ & 0.325 \\
\hline Dominant & $92(23.41)$ & $173(21.31)$ & 0.408 & $1.13(0.85-1.51)$ & 0.409 & $1.13(0.85-1.51)$ & 0.400 \\
\hline Recessive & $384(97.71)$ & $799(98.40)$ & 0.402 & $1.44(0.61-3.40)$ & 0.405 & $1.44(0.61-3.40)$ & 0.407 \\
\hline \multicolumn{8}{|c|}{ Combine risk genotypes ${ }^{c}$} \\
\hline $0 \mathrm{~d}$ & $232(59.03)$ & $527(64.90)$ & 0.132 & 1.00 & & 1.00 & \\
\hline $1^{\mathrm{d}}$ & $119(30.28)$ & $206(25.37)$ & & $1.31(1.00-1.73)$ & 0.052 & $1.31(1.00-1.72)$ & 0.054 \\
\hline $2^{\mathrm{d}}$ & $42(10.69)$ & $79(9.73)$ & & $1.21(0.81-1.81)$ & 0.361 & $1.21(0.81-1.82)$ & 0.354 \\
\hline 0 & $232(59.03)$ & $527(64.90)$ & & 1.00 & & 1.00 & \\
\hline $1-2$ & $161(40.97)$ & $285(35.10)$ & 0.048 & $1.28(1.002-1.64)$ & 0.048 & $1.28(1.001-1.64)$ & 0.049 \\
\hline
\end{tabular}

a $\chi^{2}$ test for genotype distributions between neuroblastoma cases and controls.

$\mathrm{b}$ Adjusted for age and gender.

c Risk genotypes were rs1800975 TT, and rs3176752 GT/TT.

d 0 was no risk genotype, 1 was rs 1800975 TT or rs3176752 GT/TT, 2 was rs1800975 TT and rs3176752 GT/TT.

Table 2. Stratification analysis of XPA gene polymorphisms with neuroblastoma susceptibility

\begin{tabular}{|c|c|c|c|c|c|c|c|c|c|c|c|c|}
\hline \multirow[t]{2}{*}{ Variables } & \multicolumn{2}{|c|}{$\begin{array}{l}\text { rs1800975 } \\
\text { (cases/controls) }\end{array}$} & \multirow{2}{*}{$\begin{array}{l}\text { Adjusted OR a } \\
(95 \% \mathrm{CI})\end{array}$} & \multirow[t]{2}{*}{$P$ a } & \multicolumn{2}{|c|}{$\begin{array}{l}\text { rs3176752 } \\
\text { (cases/controls) }\end{array}$} & \multirow{2}{*}{$\begin{array}{l}\text { Adjusted OR a } \\
(95 \% \mathrm{CI})\end{array}$} & \multirow[t]{2}{*}{$P$ a } & \multicolumn{2}{|c|}{$\begin{array}{l}\text { Risk genotypes } \\
\text { (cases/controls) }\end{array}$} & \multirow{2}{*}{$\begin{array}{l}\text { Adjusted OR a } \\
(95 \% \mathrm{CI})\end{array}$} & \multirow[t]{2}{*}{$P$ a } \\
\hline & TT & $\mathrm{TC} / \mathrm{CC}$ & & & GG & GT/TT & & & $0-1$ & 2 & & \\
\hline \multicolumn{13}{|l|}{ Age, month } \\
\hline$\leq 18$ & $31 / 64$ & $95 / 241$ & $0.81(0.50-1.33)$ & 0.411 & $93 / 240$ & $33 / 65$ & $1.31(0.81-2.12)$ & 0.273 & $78 / 203$ & $48 / 102$ & $1.23(0.80-1.89)$ & 0.357 \\
\hline$>18$ & $80 / 127$ & $187 / 380$ & $0.78(0.56-1.08)$ & 0.133 & $208 / 399$ & $59 / 108$ & $1.05(0.73-1.51)$ & 0.782 & $154 / 324$ & $113 / 183$ & $1.31(0.96-1.77)$ & 0.085 \\
\hline \multicolumn{13}{|l|}{ Gender } \\
\hline Females & $43 / 74$ & $125 / 268$ & $0.81(0.52-1.24)$ & 0.324 & $133 / 268$ & $35 / 74$ & $0.94(0.60-1.48)$ & 0.798 & $104 / 226$ & $64 / 116$ & $1.19(0.81-1.75)$ & 0.364 \\
\hline Males & $68 / 117$ & $157 / 353$ & $0.78(0.55-1.11)$ & 0.169 & $168 / 371$ & $57 / 99$ & $1.27(0.87-1.84)$ & 0.213 & $128 / 301$ & $97 / 169$ & $1.33(0.96-1.84)$ & 0.086 \\
\hline \multicolumn{13}{|l|}{ Sites of origin } \\
\hline Adrenal gland & $43 / 191$ & $110 / 621$ & $0.80(0.54-1.19)$ & 0.269 & $119 / 639$ & $34 / 173$ & $1.06(0.70-1.61)$ & 0.777 & $88 / 527$ & $65 / 285$ & $1.35(0.95-1.92)$ & 0.096 \\
\hline Retroperitoneal & $24 / 191$ & $63 / 621$ & $0.80(0.49-1.33)$ & 0.392 & $68 / 639$ & $19 / 173$ & $1.02(0.60-1.75)$ & 0.931 & $53 / 527$ & $34 / 285$ & $1.19(0.75-1.87)$ & 0.461 \\
\hline Mediastinum & $32 / 191$ & $77 / 621$ & $0.73(0.47-1.13)$ & 0.158 & $80 / 639$ & $29 / 173$ & $1.33(0.84-2.10)$ & 0.226 & $63 / 527$ & $46 / 285$ & $1.36(0.91-2.05)$ & 0.138 \\
\hline Others & $10 / 191$ & $26 / 621$ & $0.79(0.37-1.66)$ & 0.528 & $27 / 639$ & $9 / 173$ & $1.22(0.56-2.65)$ & 0.613 & $22 / 527$ & $14 / 285$ & $1.19(0.60-2.36)$ & 0.624 \\
\hline \multicolumn{13}{|l|}{ Clinical stages } \\
\hline $\mathrm{I}+\mathrm{II}+4 \mathrm{~s}$ & $44 / 191$ & $118 / 621$ & $0.81(0.55-1.19)$ & 0.297 & $119 / 639$ & $43 / 173$ & $1.33(0.90-1.96)$ & 0.150 & $95 / 527$ & $67 / 285$ & $1.32(0.93-1.86)$ & 0.115 \\
\hline III+IV & $64 / 191$ & $147 / 621$ & $0.72(0.51-1.01)$ & 0.055 & $167 / 639$ & $44 / 173$ & $0.98(0.68-1.43)$ & 0.929 & $123 / 527$ & $88 / 285$ & $1.31(0.96-1.79)$ & 0.089 \\
\hline
\end{tabular}

a Adjusted for age and gender without the corresponding stratification factor.

Table 3. Association between inferred haplotypes of XPA gene and neuroblastoma susceptibility

\begin{tabular}{|c|c|c|c|c|c|c|}
\hline Haplotypes a & Cases $(\mathrm{N}=786)$ & Controls $(\mathrm{N}=1624)$ & Crude OR $(95 \% \mathrm{CI})$ & $P$ & Adjusted OR b $(95 \%$ CI) & $P$ b \\
\hline CG & $317(40.33)$ & $716(44.09)$ & 1.00 & & 1.00 & \\
\hline $\mathrm{CT}$ & $50(6.36)$ & $94(5.79)$ & $1.20(0.83-1.74)$ & 0.328 & $1.20(0.83-1.74)$ & 0.328 \\
\hline TG & $368(46.82)$ & $722(44.46)$ & $1.15(0.96-1.38)$ & 0.130 & $1.15(0.96-1.38)$ & 0.134 \\
\hline TT & $51(6.49)$ & $92(5.67)$ & $1.25(0.87-1.81)$ & 0.230 & $1.26(0.87-1.81)$ & 0.226 \\
\hline
\end{tabular}

a The haplotypes order were rs1800975 and rs3176752.

b Obtained in logistic regression models with adjustment for age and gender. 
Although this study has its own merits, limitation accompanies. First, as a hospital-based case-control study, selection bias is inevitable. Second, the sample size of this case-control study is relatively small, especially for the stratification analysis. As a result, the statistical power was compromised. Thus, these findings call for replication studies in larger sample size. Third, the number of the analyzed SNPs is limited. Fourth, neuroblastoma is a heterogeneous disease with complex etiology; thus, genetic analysis alone is far more enough to elucidate its etiology. Yet due to the nature of retrospective investigations, we failed to obtain other risk exposing factors, such as paternal exposures, living environment, and dietary intake. Further studies including environmental factors analysis and gene-environment interaction analysis are warranted. Fifth, the conclusion obtained from this study could not be directly extrapolated to other ethnicities, as all the included subjects were restricted to unrelated Chinese Han ethnicity.

In summary, we first investigated the association of XPA gene polymorphisms with neuroblastoma risk. Our results indicated that no single XPA gene polymorphism could influence neuroblastoma risk. Ongoing epidemiological studies with larger samples from different ethnicities are needed to further elucidate the role of XPA gene polymorphisms in neuroblastoma tumorigenesis.

\section{Abbreviations}

GWAS, genome-wide association study; SNP, single nucleotide polymorphism; NER, nucleotide excision repair; XPA, xeroderma pigmentosum complementary group A, HWE, Hardy-Weinberg equilibrium; $\mathrm{OR}$, odds ratio; $\mathrm{CI}$, confidence interval.

\section{Acknowledgements}

This work was supported by grants from National Natural Science Foundation of China (No: 81502187), and Pearl River S\&T Nova Program of Guangzhou (No: 201710010086).

\section{Competing Interests}

The authors have declared that no competing interest exists.

\section{References}

1. Matthay KK, Maris JM, Schleiermacher G, Nakagawara A, Mackall CL, Diller L, et al. Neuroblastoma. Nat Rev Dis Primers. 2016; 2: 16078.

2. Cheung NK, Dyer MA. Neuroblastoma: developmental biology, cancer genomics and immunotherapy. Nat Rev Cancer. 2013; 13: 397-411.

3. Bao PP, Li K, Wu CX, Huang ZZ, Wang CF, Xiang YM, et al. [Recent incidences and trends of childhood malignant solid tumors in Shanghai, 2002-2010]. Zhonghua Er Ke Za Zhi. 2013; 51: 288-94.

4. Gurney JG, Ross JA, Wall DA, Bleyer WA, Severson RK, Robison LL. Infant cancer in the U.S.: histology-specific incidence and trends, 1973 to $1992 . \mathrm{J}$ Pediatr Hematol Oncol. 1997; 19: 428-32.

5. Maris JM, Hogarty MD, Bagatell R, Cohn SL. Neuroblastoma. Lancet. 2007; 369: 2106-20.
6. Shimada H, Ambros IM, Dehner LP, Hata J, Joshi VV, Roald B, et al. The International Neuroblastoma Pathology Classification (the Shimada system). Cancer. 1999; 86: 364-72.

7. Maris JM. Recent advances in neuroblastoma. N Engl J Med. 2010; 362: 2202-11.

8. Esposito MR, Aveic S, Seydel A, Tonini GP. Neuroblastoma treatment in the post-genomic era. J Biomed Sci. 2017; 24: 14

9. Mosse YP, Laudenslager M, Longo L, Cole KA, Wood A, Attiyeh EF, et al. Identification of ALK as a major familial neuroblastoma predisposition gene. Nature. 2008; 455: 930-5.

10. Chen Y, Takita J, Choi YL, Kato M, Ohira M, Sanada M, et al. Oncogenic mutations of ALK kinase in neuroblastoma. Nature. 2008; 455: 971-4.

11. Bourdeaut F, Trochet D, Janoueix-Lerosey I, Ribeiro A, Deville A, Coz C, et al. Germline mutations of the paired-like homeobox 2B (PHOX2B) gene in neuroblastoma. Cancer Lett. 2005; 228: 51-8.

12. Mosse YP, Laudenslager M, Khazi D, Carlisle AJ, Winter CL, Rappaport E, et al. Germline PHOX2B mutation in hereditary neuroblastoma. Am J Hum Genet. 2004; 75: 727-30.

13. Devoto M, Specchia C, Laudenslager M, Longo L, Hakonarson H, Maris J, et al. Genome-wide linkage analysis to identify genetic modifiers of ALK mutation penetrance in familial neuroblastoma. Hum Hered. 2011; 71: 135-9.

14. Cook MN, Olshan AF, Guess HA, Savitz DA, Poole C, Blatt J, et al. Maternal medication use and neuroblastoma in offspring. Am J Epidemiol. 2004; 159: 721-31.

15. Menegaux F, Olshan AF, Neglia JP, Pollock BH, Bondy ML. Day care, childhood infections, and risk of neuroblastoma. Am J Epidemiol. 2004; 159: 843-51.

16. Maris JM, Mosse YP, Bradfield JP, Hou C, Monni S, Scott RH, et al. Chromosome $6 \mathrm{p} 22$ locus associated with clinically aggressive neuroblastoma. N Engl J Med. 2008; 358: 2585-93.

17. Capasso M, Devoto M, Hou C, Asgharzadeh S, Glessner JT, Attiyeh EF, et al. Common variations in BARD1 influence susceptibility to high-risk neuroblastoma. Nat Genet. 2009; 41: 718-23.

18. Wang K, Diskin SJ, Zhang H, Attiyeh EF, Winter C, Hou C, et al. Integrative genomics identifies LMO1 as a neuroblastoma oncogene. Nature. 2011; 469: 216-20.

19. Nguyen le B, Diskin SJ, Capasso M, Wang K, Diamond MA, Glessner J, et al. Phenotype restricted genome-wide association study using a gene-centric approach identifies three low-risk neuroblastoma susceptibility Loci. PLoS Genet. 2011; 7: e1002026.

20. Diskin SJ, Capasso M, Schnepp RW, Cole KA, Attiyeh EF, Hou C, et al. Common variation at $6 \mathrm{q} 16$ within HACE1 and LIN28B influences susceptibility to neuroblastoma. Nat Genet. 2012; 44: 1126-30.

21. Diskin SJ, Capasso M, Diamond M, Oldridge DA, Conkrite K, Bosse KR, et al. Rare variants in TP53 and susceptibility to neuroblastoma. J Natl Cancer Inst. 2014; 106: dju047.

22. He J, Zhong W, Zeng J, Zhu J, Zhang R, Wang F, et al. LMO1 gene polymorphisms contribute to decreased neuroblastoma susceptibility in a Southern Chinese population. Oncotarget. 2016; 7: 22770-8.

23. He J, Yang T, Zhang R, Zhu J, Wang F, Zou Y, et al. Potentially functional polymorphisms in the LIN28B gene contribute to neuroblastoma susceptibility in Chinese children. J Cell Mol Med. 2016; 20: 1534-41.

24. Zhang R, Zou Y, Zhu J, Zeng X, Yang T, Wang F, et al. The Association between GWAS-identified BARD1 Gene SNPs and Neuroblastoma Susceptibility in a Southern Chinese Population. Int J Med Sci. 2016; 13: 133-8.

25. Zhang J, Lin H, Wang J, He J, Zhang D, Qin P, et al. LMO1 polymorphisms reduce neuroblastoma risk in Chinese children: a two-center case-control study. Oncotarget. 2017; 8: 65620-6.

26. He J, Wang F, Zhu J, Zhang Z, Zou Y, Zhang R, et al. The TP53 gene rs1042522 $\mathrm{C}>\mathrm{G}$ polymorphism and neuroblastoma risk in Chinese children. Aging (Albany NY). 2017; 9: 852-9.

27. Stadler ZK, Thom P, Robson ME, Weitzel JN, Kauff ND, Hurley KE, et al Genome-wide association studies of cancer. J Clin Oncol. 2010; 28: 4255-67.

28. Wood RD, Mitchell M, Sgouros J, Lindahl T. Human DNA repair genes. Science. 2001; 291: 1284-9.

29. Gillet LC, Scharer OD. Molecular mechanisms of mammalian global genome nucleotide excision repair. Chem Rev. 2006; 106: 253-76.

30. Berwick M, Vineis P. Markers of DNA repair and susceptibility to cancer in humans: an epidemiologic review. J Natl Cancer Inst. 2000; 92: 874-97.

31. Friedberg EC. How nucleotide excision repair protects against cancer. Nat Rev Cancer. 2001; 1: 22-33.

32. Christmann M, Tomicic MT, Roos WP, Kaina B. Mechanisms of human DNA repair: an update. Toxicology. 2003; 193: 3-34.

33. Cleaver JE. Common pathways for ultraviolet skin carcinogenesis in the repair and replication defective groups of xeroderma pigmentosum. J Dermatol Sci. 2000; 23: 1-11.

34. Sugitani N, Shell SM, Soss SE, Chazin WJ. Redefining the DNA-binding domain of human XPA. J Am Chem Soc. 2014; 136: 10830-3.

35. Scharer OD. Nucleotide excision repair in eukaryotes. Cold Spring Harb Perspect Biol. 2013; 5: a012609.

36. Dziki L, Dziki A, Mik M, Majsterek I, Kabzinski J. Modulation of Colorectal Cancer Risk by Polymorphisms in 51Gln/His, 64lle/Val, and 148Asp/Glu of APEX Gene; 23Gly/Ala of XPA Gene; and 689Ser/Arg of ERCC4 Gene. Gastroenterol Res Pract. 2017; 2017: 3840243. 
37. Lu B, Li J, Gao Q, Yu W, Yang Q, Li X. Laryngeal cancer risk and common single nucleotide polymorphisms in nucleotide excision repair pathway genes ERCC1, ERCC2, ERCC3, ERCC4, ERCC5 and XPA. Gene. 2014; 542: 64-8.

38. Mei C, Hou M, Guo S, Hua F, Zheng D, Xu F, et al. Polymorphisms in DNA repair genes of $\mathrm{XRCC1}, \mathrm{XPA}, \mathrm{XPC}, \mathrm{XPD}$ and associations with lung cancer risk in Chinese people. Thorac Cancer. 2014; 5: 232-42.

39. Ruiz-Cosano J, Torres-Moreno D, Conesa-Zamora P. Influence of polymorphisms in ERCC5, XPA and MTR DNA repair and synthesis genes in B-cell lymphoma risk. A case-control study in Spanish population. J BUON. 2013; 18: 486-90.

40. He J, Zou Y, Liu X, Zhu J, Zhang J, Zhang R, et al. Association of Common Genetic Variants in Pre-microRNAs and Neuroblastoma Susceptibility: A Two-Center Study in Chinese Children. Mol Ther Nucleic Acids. 2018; 11: 1-8.

41. Zhang Z, Chang $Y$, Jia W, Zhang J, Zhang R, Zhu J, et al. LINC00673 rs11655237 C $>$ T confers neuroblastoma susceptibility in Chinese population. Biosci Rep. 2018; 38: BSR20171667.

42. Zhuo ZJ, Liu W, Zhang J, Zhu J, Zhang R, Tang J, et al. Functional Polymorphisms at ERCC1/XPF Genes Confer Neuroblastoma Risk in Chinese Children. EBioMedicine. 2018; 30: 113-9.

43. Zhang J, Zhuo ZJ, Wang J, He J, Yang L, Zhang D, et al. CASC15 gene polymorphisms reduce neuroblastoma risk in Chinese children. Oncotarget. 2017; 8: 91343-9.

44. Wu Q, Zhuo ZJ, Zeng J, Zhang J, Zhu J, Zou Y, et al. Association between NEFL Gene Polymorphisms and Neuroblastoma Risk in Chinese Children: A Two-Center Case-Control Study. J Cancer. 2018; 9: 535-9.

45. He J, Qiu LX, Wang MY, Hua RX, Zhang RX, Yu HP, et al. Polymorphisms in the XPG gene and risk of gastric cancer in Chinese populations. Hum Genet. 2012; 131: 1235-44.

46. Li J, Zou L, Zhou Y, Li L, Zhu Y, Yang Y, et al. A low-frequency variant in SMAD7 modulates TGF-beta signaling and confers risk for colorectal cancer in Chinese population. Mol Carcinog. 2017; 56: 1798-807.

47. Lou J, Gong J, Ke J, Tian J, Zhang Y, Li J, et al. A functional polymorphism located at transcription factor binding sites, rs6695837 near LAMC1 gene, confers risk of colorectal cancer in Chinese populations. Carcinogenesis. 2017; 38: $177-83$.

48. Gong J, Tian J, Lou J, Wang X, Ke J, Li J, et al. A polymorphic MYC response element in KBTBD11 influences colorectal cancer risk, especially in interaction with a MYC regulated SNP rs6983267. Ann Oncol. 2018; 29: 632-9.

49. Zou D, Lou J, Ke J, Mei S, Li J, Gong Y, et al. Integrative expression quantitative trait locus-based analysis of colorectal cancer identified a functional polymorphism regulating SLC22A5 expression. Eur J Cancer. 2018; 93: $1-9$.

50. Ikegami T, Kuraoka I, Saijo M, Kodo N, Kyogoku Y, Morikawa K, et al. Solution structure of the DNA- and RPA-binding domain of the human repair factor XPA. Nat Struct Biol. 1998; 5: 701-6.

51. States JC, McDuffie ER, Myrand SP, McDowell M, Cleaver JE. Distribution of mutations in the human xeroderma pigmentosum group A gene and their relationships to the functional regions of the DNA damage recognition protein. Hum Mutat. 1998; 12: 103-13.

52. Zienolddiny S, Campa D, Lind H, Ryberg D, Skaug V, Stangeland L, et al. Polymorphisms of DNA repair genes and risk of non-small cell lung cancer. Carcinogenesis. 2006; 27: 560-7.

53. Capasso M, Diskin SJ. Genetics and genomics of neuroblastoma. Cancer Treat Res. 2010; 155: 65-84.

54. Pan J, Lin J, Izzo JG, Liu Y, Xing J, Huang M, et al. Genetic susceptibility to esophageal cancer: the role of the nucleotide excision repair pathway. Carcinogenesis. 2009; 30: 785-92.

55. Tse D, Zhai R, Zhou W, Heist RS, Asomaning K, Su L, et al. Polymorphisms of the NER pathway genes, ERCC1 and XPD are associated with esophageal adenocarcinoma risk. Cancer Causes Control. 2008; 19: 1077-83.

56. He J, Wang F, Zhu J, Zhang R, Yang T, Zou Y, et al. Association of potentially functional variants in the XPG gene with neuroblastoma risk in a Chinese population. J Cell Mol Med. 2016; 20: 1481-90. 